\title{
Haemoccult does not reduce the need for colonoscopy in surveillance after curative resection for colorectal cancer
}

\author{
C Hall, J Griffin, P W Dykes, J Alexander Williams, M R B Keighley
}

\begin{abstract}
Patients who had undergone curative resection for colorectal cancer were studied to compare the efficacy of faecal occult blood detection (Haemoccult test) with colonoscopy in the detection of metachronous tumours. Fifty nine patients were studied and both Haemoccult testing and colonoscopy were successfully completed in 54 patients. In 37 patients, both tests were negative. One patient with a positive Haemoccult test had no colonoscopic abnormality and remains alive and well two years later. There were, however, 16 patients with negative Haemoccult tests in whom an abnormality was found on colonoscopy. In four patients, one Dukes's A cancer and seven tubulovillous adenomas were found - all neoplastic lesions that would have been missed if surveillance had been by Haemoccult alone. (Gut 1993; 34: 227-229)
\end{abstract}

Despite early scepticism of the necessity of follow up,,$^{12}$ metachronous lesions of the colon occur in $1-9 \%$ of patients after curative resection of a colorectal cancer, ${ }^{3-5}$ and local recurrence has been reported in $4-30 \%$ of these patients. ${ }^{6-8}$ The early detection of local recurrence with an aggressive surgical approach is the only chance of eradicating this local disease. ${ }^{9-11} \mathrm{It}$ is reasonable to assume that detection of metachronous lesions at an early stage should lead to the same improvement in prognosis as early detection of a primary neoplasm..$^{12}$ These two conditions alone justify surveillance of patients who have undergone curative resection.

The best examination of the remaining large bowel is probably by colonoscopy ${ }^{131+}$ but colonoscopic surveillance is not without risk, is costly, and the numbers involved may place a large burden on endoscopy units. Selective colonoscopy, however, is an attractive option.

Faecal occult blood testing is being investigated as a method of screening populations for colorectal cancer in many centres and has been shown to detect a large proportion of early lesions. ${ }^{15-17}$ It was thought that faecal occult blood testing of patients who had undergone curative resection for large bowel cancer might help select those in need of colonoscopy. This study was therefore designed to compare the results of faecal occult blood testing using Haemoccult with colonoscopy.

\section{Patients and methods}

Four hospitals participated in the study. All patients under the age of 80 years who had undergone curative resection of cancer of the large bowel were considered for the study. Each patient studied had undergone resection at least 3 years previously, in order to avoid the possibility of detecting missed synchronous lesions. We also excluded any patient who had undergone colonoscopy or barium enema in the preceding three years, and those who had large bowel symptoms.

Six day dietary restricted Haemoccult testing was performed before colonoscopy. The patient was seen in the outpatient department of their local hospital and the study was explained, instructions for Haemoccult testing and colonoscopy given, and informed consent was obtained. The study protocol can be abbreviated as follows:

Day 1 - start dietary restriction for Haemoccult;

Days 4-9 - collect six Haemoccult specimens and post completed cards in a stamped addressed envelope;

Day 10 - resume normal diet;

Day 14 - bowel preparation for colonoscopy;

Day 15 - colonoscopy.

One observer $(\mathrm{JG})$ read the cards after rehydration and recorded the results. The colonoscopist carried out the procedure without knowing the Haemoccult result, and completed a standard proforma giving colonoscopic details and histological findings where applicable. These data were forwarded to a second observer $(\mathrm{CH})$. Only after the first 60 patients were entered into the study were the Haemoccult and colonoscopy data compared and the results made available to the participating centres.

We approached 60 patients to participate in the study. One refused to perform the Haemoccult test and in two patients, the Haemoccult specimens were inadequate. There were three incomplete colonoscopies where the caecum was not reached. The results in 54 patients were available for analysis. There were 25 women and 29 men with ages ranging from 48 to 79 years with a median age of 69 years. There were four patients who had a resection for Dukes's A lesions, 28 for Dukes's B, and 22 for Dukes's C lesions. There was no morbidity associated with any part of the study.

\section{Results}

Thirty seven patients were negative on Haemoccult testing and had normal residual large bowel on colonoscopy. There was one false positive Haemoccult test in a patient who had had a right hemicolectomy for a Dukes's B lesion four years before the study. Once the positive Haemoccult result was made known to his consultant, he was recalled and had a gastroscopy, repeat colono- 
Results of Haemoccult test and colonoscopic findings in 57 patients

\begin{tabular}{|c|c|c|c|}
\hline $\begin{array}{l}\text { No of } \\
\text { patients }\end{array}$ & $\begin{array}{l}\text { Haemoccult } \\
\text { result }\end{array}$ & Colonoscopic finding & Histology \\
\hline 37 & Negative & Normal colon & - \\
\hline 4 & Negative & Anastomotic stricture & Granulation tissue \\
\hline 3 & Negative & Diverticular disease & \\
\hline 3 & Negative & 8 Benign polyps & Metaplastic polyps \\
\hline 1 & Negative & Proctitis & Radiation proctitis \\
\hline 1 & Negative & Solitary rectal ulcer & Solitary rectal ulcer \\
\hline 1 & Negative & $\begin{array}{l}1 \text { Tumour }+ \text { polyp }-0.8 \mathrm{~cm} \\
\text { diameter }\end{array}$ & $\begin{array}{l}\text { Dukes's A cancer, moderately } \\
\text { dysplastic polyp }\end{array}$ \\
\hline 1 & Negative & $\begin{array}{l}3 \text { Polyps }-1.2 \mathrm{~cm} \\
1.0 \mathrm{~cm} \text {, and } \\
0.5 \mathrm{~cm} \text { diameter }\end{array}$ & $\begin{array}{l}\text { Severely, } \\
\text { severely, and } \\
\text { moderately dysplastic respectively }\end{array}$ \\
\hline 1 & Negative & $\begin{array}{l}2 \text { Polyps }-0.8 \mathrm{~cm} \\
\text { and } 0.5 \mathrm{~cm} \text { diameter }\end{array}$ & $\begin{array}{l}\text { Moderately and } \\
\text { mildly dysplastic respectively }\end{array}$ \\
\hline 1 & Negative & 1 Polyp $-1.4 \mathrm{~cm}$ diameter & Severely dysplastic \\
\hline 1 & Positive & Normal colon & - \\
\hline
\end{tabular}

scopy, ultrasound scan of the liver, abdomen, and pelvis, and serum carcinogenic embryonic antigen; all were normal. He remains alive and well, five and a half years from the original resection.

There were 16 patients in whom the Haemoccult test was negative but colonoscopy showed some abnormality. In 12 it was benign: four had anastomotic strictures with granulations, three had diverticular disease, three had eight metaplastic polyps between them (the largest being $8 \mathrm{~mm}$ diameter), one patient had radiation proctitis after adjuvant postoperative radiotherapy and one had rectal prolapse with a solitary rectal ulcer proved on biopsy and histology. Four patients had neoplastic lesions, all missed by Haemoccult. The results are summarised in the Table.

\section{Discussion}

There have been other reports comparing the efficacy of surveillance after colonic resection by Haemoccult and colonoscopy. ${ }^{18}$ In one study of 100 patients, 15 were positive on occult blood testing; three of these had adenomas and three others had a local recurrence. Negative Haemoccult tests were reported in 85 , four of whom had adenomas and 10 what were described as 'other polyps.' Unfortunately, in this study, the Haemoccult result was made known to the patients before colonoscopy. While there was an $87 \%$ colonoscopy compliance rate in the Haemoccult positive group, it was only $66 \%$ in the negative group with 19 patients refusing colonoscopy and being perhaps falsely reassured by their results. ${ }^{18}$

Our protocol was designed to try and avoid these pitfalls. We counselled each patient on the need for follow up and the importance of colonoscopy was explained. We then described the Haemoccult as a subsidiary, but not essential, test. Only one patient refused to perform the Haemoccult test and subsequently had a normal colonoscopy. Most patients appreciated that they were in a high risk group and compliance was therefore good. Two other patients failed to perform Haemoccult testing correctly.

The Haemoccult test was chosen as it was still considered to be the gold standard of faecal occult blood testing kits. ${ }^{19}$ Other tests, such as HaemoQuant (Smith Kline Diagnostics), detect the porphyrin-like moiety of haemoglobin, but are probably too sensitive to produce a significant decrease in colonoscopy,$^{20}$ while human haemoglobin immunassays may be more specific but require further evaluation."1

A six day dietary restricted test was chosen to give the best opportunity to pick up intermittent bleeding ${ }^{22}$ while excluding false positives caused by peroxidases in the diet. ${ }^{23}$ Although these two restrictions decrease the compliance rate in screening,,$^{22}$ in a well motivated, high risk group, compliance was not a problem and so these precautions were considered worthwhile. Because of the time between collection and posting of the occult blood tests and the processing of the test cards, the rehydration technique was used as this has been shown to almost double the sensitivity, irrespective of storage delay, particularly in low levels of bleeding encountered in lesions of the left colon. ${ }^{2+}$

Colonoscopy rather than barium enema was chosen to examine the remaining colon. Two studies comparing double contrast barium enema with colonoscopy in the detection of colonic disease have shown colonoscopy to have a superior diagnostic rate $(67 \%$ detection on barium enema $v 91 \%$ with colonoscopy ${ }^{13}$ and $64 \%$ detection on barium enema $v 95 \%$ on colonoscopy. ${ }^{25}$ We had a $95 \%$ successful colonoscopic examination without morbidity, and in six patients (three with metaplastic polyps and three with adenomas) the diagnostic procedure was also therapeutic.

Many reported early metachronous lesions are in fact undetected synchronous lesions ${ }^{102627}$ which may be advanced and therefore more likely to give positive Haemoccult results, and so this may bias the results in favour of occult blood testing. We tried to exclude synchronous lesions by insisting that all patients should be a minimum of three years from their primary resection.

Our results do not justify reliance on Haemoccult testing as a means of surveillance. Of our 53 patients with negative occult blood testing, 16 had an abnormality detected on colonoscopy. One can, perhaps, dismiss the three with diverticular disease and the three with metaplastic polyps as being unlikely lesions to bleed, but the anastomotic granulations, radiation proctitis, and the solitary rectal ulcer should all have been expected to give positive tests. Moreover, the Dukes's A cancer and seven adenomas in four patients were all undetected by Haemoccult, the very lesions the test was designed to detect.

Our results mirror those of any other group that has tried to study high risk and symptomatic subjects using occult blood testing. Using Haemoccult to screen first degree relatives calculated to have a one in 17 risk of colorectal cancer, 13 out of 57 patients with negative Haemoccult tests had adenomas, one having a carcinoma in situ, giving a negative predictive value of $78 \% .^{28}$

Screening symptomatic patients is no better. In a study of symptomatic patients, Haemoccult detected only 13 out of 24 patients with colorectal cancer. ${ }^{29}$ When comparing Haemoccult with double contrast barium enema and colonoscopy in the detection of colorectal cancers, Haemoccult detected only $26 \%$ of Dukes's A lesions, $69 \%$ of Dukes's B, and $64 \%$ of Dukes's C cancers.' Tate et al concluded that in symptomatic patients 
a negative Haemoccult result was unreliable and should not influence patient management. ${ }^{30}$ Our study has shown that Haemoccult testing is an unreliable method of detecting metachronous lesions after curative colonic resection. It is not even complimentary to colonoscopy, and we cannot advise its use for this purpose.

We thank the following hospitals and consultants for entering their patients into the study: Birmingham General Hospital - Mr G D Oates and $\mathrm{MrN} J$ Dorricot; Kidderminster General Hospital - Mr P Armitstead and Mr W Gillison; East Birmingham Hospital - Mr G Sokhi; North Staffordshire Royal Infirmary - Dr C Swan. We would also like to thank Norwich Eaton Ltd, Gosforth NE3 ILR for supplying the Haemoccult tests (Smith, Kline \& French Instruments, USA) and Mr R C Hinman for typing the manuscript.

1 Tornqvist A, Ekelund G, Leandoer L. The value of intensive follow up after curative resection for colorectal cancer. BrF Surg 1982; 69: 725-8.

2 Cochrance JPS, Williams JT, Faber RG, Slack WW. Value of outpatient follow up after curative surgery for cancer of the large bowel. $B M \mathcal{F}$ 1980; 280: 593-5.

3 Bülow S, Svendsen LB, Mellemgaard A. Metachronous colorectal carcinoma. BrF Surg 1990; 77: 502-5.

4 Kiefer PJ, Thorson AG, Christensen MA. Metachronous colorectal cancer. Dis Colon Rectum 1986; 29: 378-82.

5 Heald RJ, Lockhart-Mummery HE. The lesion of the second cancer of the large bowel. Br 7 Surg 1972; 59: 16-19.

6 Phillips RKS, Hittinger R, Blesovsky L, Fry JS, Fielding LP. Local recurrence following curative surgery for large bowel cancer I. The overall picture. Br F Surg 1984; 71: 12-16

7 Karaniia ND, Schache DJ, North WRS, Heald RJ. "Close shave' in anterior resection. Brf Surg 1990; 77: 510-2

8 Hurst PA, Prout WG, Kelly JM, Bannister JJ, Walker RT. Local recurrence after low anterior resection using the staple gun. BrF Surg 1982; 69: 275-6.

9 Allum WH, Ambrose NS, Fielding JWL, Chan KK. Selective salvage surgery in gastrointestinal and gynaecological cancer. Ann R Coll Surg Engl 1990; 72: 2-5.

10 Schiessel R, Wunderlich M, Herbst F. Local recurrence of colorectal cancer - effect of early detection and aggressive surgery. BrF Surg 1986; 73: 342-4.

11 Vassilopoulos PP, Yoon JM, Ledesma ES, Mittelme A. Treatment of recurrence of adenocarcinoma of the colon and rectum at the anastomotic site. Surg Gynecol Obstet 1981; 152: $777-80$.

12 Heald RJ. Synchronous and metachronous carcinomas of the colon and rectum. Ann R Coll Surg Engl 1990; 72: 172-4.
13 Durdey P, Weston PMT, Williams NS. Colonoscopy or barium enema as the initial investigation of colonic disease. Lancet 1987; ii: 5+9-57.

14 Albridge MS, Sims AJW. Colonoscopy findings in symptomatic patients without Xray evidence of colonic neoplasm. Lancet 1986; ii: $833-4$

15 Hardcastle JD, Thomas WM, Chamberlain J, Pve G, Sheffield J, James PD, et al. Randomised controlled trial of faecal occult blood screening for colorectal cancer. Lancet 1989; i: $1160-4$.

16 Kewenter J, Bjork S, Haglind E, Smith E, Svanvik J, Ahren C. Screening and rescreening for colorectal cancer: a controlled trial of faecal occult blood testing in 27700 subjects. Cancer 1988; 62: 645-51.

17 Kranborg O, Fenger C, Sondergaard O, Pedersen KM, Olsen J. Initial mass screening for colorectal cancer with fecal occult blood test. Scand F Gastroenterol 1987; 22: 677-86.

18 Aste H, Giacchero A, Pugliese V, Santi L. Occult blood testing in asymptomatic patients previously resected for colorectal cancer. Cancer Detect Prev 1984; 7: 237-40.

19 Ransohoff DF, Lang CA. Screening for colorectal cancer. NEngl if Med 1991; 325: 37-41.

20 Ahlquist DA, McGill DB, Schwart\% S, Taylor WF, Owen RA. Faecal blood levels in health and disease: a study using HaemoQuant. N Engl f Med 1985; 312: 1422-8.

21 Sangster CL Barrows GH Jarret DD Immunochemical detection of faecal occult blood in the faecal smear punch disc test: a new non-invasive screening test for colorectal cancer. Cancer 1980; 45: 1099-102.

22 Thomas WM, Pye G, Hardcastle JD, Mangham CM. Faecal occult blood screening for colorectal neoplasia: a randomised trial of three days or six days of tests. Br. F Surg 1990; 77: 277-9.

23 Thomas WM, Pye G, Hardcastle JD, Chamberlain J, Charnley RM. Role of dietary restriction of Haemoccult screening for colorectal cancer. BrF Surg 1989; 76: 976-8.

24 Macrae FA, St John DJB. Relationship between patterns of bleeding and Haemoccult sensitivity in patients with colorbleeding and Haemoccult sensitivity in patients with color-

25 Kalra L, Hamlyn AN. Comparative evaluation of investigations for colorectal carcinoma in symptomatic patients. tions for colorectal carcinoma
Postgrad Med F 1984; 64: 666-8.

26 Finan PJ, Ritchie JK, Hawley PR. Synchronous and 'early' metachronous carcinomas of the colon and rectum. BrF S urg 1987; 74: 945-7.

27 Cunliffe WJ, Haselton PS, Tweedle DF, Schofield PF. Incidence of synchronous and metachronous colorectal cancer. BrF Surg 1984; 71: 941-3.

28 Houlston RS, Murday V, Harocopos C, Williams CB, Slack J. Screening and genetic counselling for relatives of patients with colorectal cancer in a family cancer clinic. BM7 1990; 301: 366-8.

29 Pye G,Jackson J, Thomas WM, Hardcastle JD. Comparison of Coloscreen self test and Haemoccult faecal occult blood tests in the detection of colorectal cancer in symptomatic patients. Br F Surg 1990; 77: 630-1.

30 Tate JJ, Northway J, Royle GT, Taylor I.Faecal occult blood testing in symptomatic patients: comparison of three tests. BrF Surg 1990; 77: 523-6. 